\title{
Okula Yönelik Güdü Envanterinin Türkçeye Uyarlanması*
}

\section{The Turkish Adaptation of Inventory of School Motivation}

\author{
Öner USLU**, Tuncay ÖĞRETMEN***
}

\begin{abstract}
Öz: Bu çalışmanın amacı Okula Yönelik Güdü Envanterinin (OYGE) Türkçe'ye uyarlanmasıdar. Uluslararası alanda birçok kültüre uyarlanmış olan OYGÖ 43 madde, dört boyut her boyutun altında iki alt faktör olmak üzere toplam sekiz fatörden oluşmaktadır. Bu faktörler görev yönelimi, çaba, yarışma, sosyal güç, işbirliği, sosyal alaka, övgü ve ödüldür. Orijinal ölçek üç ayrı dil uzmanı tarafından İngilizceden Türkçeye çevrilmiş, başka üç uzman tarafından ise Türkçe çeviriler tekrar İngilizceye çevrilmiş, sonrasında araştırmacı ve başka bir dil uzmanı tarafindan maddeler seçilmiştir. Daha sonra altı akademisyen, iki Türkçe öğretmeni ve altı lisans öğrencisinden uzman görüşü alınmıştır. Ölçeğin orijinal faktör yapısının Türkçe form için de geçerli olup olmadığının test edilmesi amacıyla 554 lisans öğrencisinden veri toplanmış, doğrulayıcı faktör analizi sonucu sekiz faktörlü yapının Türkçe form için de doğrulandığı görülmüştür. Ölçeğin faktörlerine ilişkin güvenirlik analizi sonuçları da yeterli bulunmuştur. Daha sonra ölçüt geçerliğinin incelenmesi amacıyla Okula Yönelik Tutum, Genel Özyeterlik ve OYGÖ 784 lisans öğrencisine uygulanmıştır. Bulgulara göre, okula yönelik güdü, okula yönelik tutum ve genel öz yeterlik arasında anlamlı ilişkiler bulunmaktadır. Sonuç olarak OYGÖ'nün Türkçe formunun lisans öğrencileri için geçerli ve güvenilir olduğu söylenebilir.

Anahtar Kelimeler: Okula yönelik güdü, okula yönelik tutum, genel öz yeterlik, ölçek uyarlama
\end{abstract}

\begin{abstract}
The aim of this study is adapting The Inventory of School Motivation (ISM) to. The ISM which is adapted to many cultures consists of 43 items, four dimensions, and eight sub-dimensions. This sub-dimensions are named as task involvement, effort, competition, social power, affiliation, social concern, praise and token. Firstly translation and re-translation were done by six experts. Then researcher and an expert selected the most eligible items and the selected items were sent to the expert review so the final form of Turkish version was prepared. The Turkish version of ISM was administered to 554 university students, and confirmatory factorial analysis (CFA) was conducted to test if the original factorial structure is also valid for Turkish version. The results show that the eight factored structure of ISM is also valid for Turkish version. The reliability coefficients were also found to be sufficient for all the sub dimensions. Then the criterion validity of ISM's Turkish version was tested by examining the correlation between ISM, Attitudes Towards School Scale (ATSS) and General Self-Efficacy Scale (GSES). The data were collected from 784 university students, who had not attended the first implementation of ISM, to test the correlations. The ISM has meaningful correlations with similar structured scales and it means that criterion-related validity of ISM was also confirmed. Consequently, the ISM was adapted to Turkish Culture by this study. The eight factored structure of the scale is also valid and reliable for Turkish Culture.

Keywords: School motivation, attitudes towards school, general self-efficacy, scale adaptation
\end{abstract}

\section{Giriş}

Eğitim sisteminin başarısının değerlendirilmesi için öğrencilerin akademik başarılarının yanı sıra duyuşsal özelliklerinin gelişiminin de incelenmesi gerekmektedir. Okula yönelik güdü okulla ilgili incelenmesi gereken önemli duyuşsal özelliklerden birisidir (Ganotice, Bernardo ve King, 2012; McInerney ve Sinclair, 1991; Nasser ve McInerney, 2016). Güdü bir göreve başlama, bu çalışmayı sürdürme ve sonlandırmak için sebat gösterme gibi birçok duyguyu

\footnotetext{
*Bu araștırma Ege Üniversitesi Bilimsel Araştırma Projelerince (Proje no:16-EĞF-007) desteklenmiş ve 26-28 Ekim 2017 Tarihleri Arasında Marmariste yapılan 5. Uluslararası Eğitim Programları ve Öğretim Kongresinde Sözlü Bildiri Olarak Sunulmuştur.

**Dr. Öğretim Üyesi, Ege Üniversitesi Eğitim Fakültesi, İzmir - Türkiye e-posta: oner.uslu@ @ge.edu.tr

***Doç. Dr. Ege Üniversitesi Eğitim Fakültesi, İzmir - Türkiye e-posta: tuncay.ogretmen@ ege.edu.tr
} 
harekete geçiren içsel bir güç olarak tanımlanabilir (Açıkgöz, 2003; Schunk, Pintrich ve Meece, 2008). Güdünün çoğunlukla ihtiyaçlar, yönelimler, beklentiler ve amaçlarla ilişkili olduğu belirtilmektedir (Maehr, 1984). Güdüsü yüksek bireylerin tereddüt etmeden, yoğun ve kararlı bir şekilde göreve odaklandıkları görülmektedir (Açıkgöz, 2003). Maher'in (1984) kişisel yatırım kuramı insan güdülenmesini açıklamak için insanların zamanlarını ve enerjilerini neden belirlik aktivite yada konulara yönlendirdiklerini açıklamaya çalışır. Sosyal bilişsel bir yapı içinde ele alındığında kişisel yatırım kuramı bireylerin durumları nasıl değerlendirdiği, kişisel yatırım için neyi değerli buldukları ve kendilerine nasıl yatırım yaptıklarını belirlemede sosyo-kültürel ve durumsal faktörlerin önemli olduğunu belirtmektedir (Maehr, 1984; Xu ve Barnes, 2011). Davranışa yönelik kişisel yatırım için teşvik ediciler görev, ego, sosyal ve dişsal olarak sıralanabilir. Görev teşvikleri göreve ve çaba amaçlarına odaklanır; ego teşvikleri yarışma ve sosyal güç amaçlıdır, sosyal teşvikler aidiyet ve sosyal ilgi odaklıdır, dışsal teşvikler ise övgü ve ödüle odaklanır (Maehr, 1984). Bu nedenle öğrencilerin okula yönelik güdülerinin anlaşılması önemlidir. Geçerli ve güvenilir ölçme araçlarıyla öğrencilerin okula yönelik güdülerini ölçtüğümüzde, hem öğrencilerin güdülerinin düzeyini belirleyebilir, hem de okula yönelik güdünün hangi değişkenlerle ilişkili olduğunu ortaya koyabiliriz. Ancak Türkçe alanyazın incelendiğinde ortaokul ve lise düzeyinde öğrencilerin okula yönelik güdülerini inceleyen bazı araştırmalar rastlanmakla birlikte (Aktaş, 2009; Altun, 2010; Yavuz, 2006), lisans düzeyinde öğrencilerin okula yönelik güdülerini inceleyeme dönük ölçme araçlarına rastlanmamıştır. Bu nedenle lisans öğrencilerin okula yönelik güdülerini ölçebilecek geçerli ve güvenilir bir ölçme aracı bulunmadığı görülmektedir.

Alanyazında öğrencilerin akademik başarıları ve okula ilişkin duyuşsal özelliklerini kültürler arası kıyaslamaya çalışan birçok araştırma bulunmaktadır (King, Ganotice ve Watkins, 2012; McInerney ve Sinclair, 1991; Suliman ve McInerney, 2006; Xu ve Barnes, 2011). Bu çalışmaların yürütülebilmesi için ise kültürler arası geçerliliğe sahip güvenilir ölçme araçlarına ihtiyaç duyulmaktadır. Uluslararası alanda geçerliliği kabul görmüş ölme araçlarının farklı kültürlere uyarlanması, bu karşılaştırmalı çalışmalara olanak sağlayacaktır (King ve diğerleri, 2012). Dolayısıyla bu araştırmada McInerney ve Sinclair (1991) tarafından geliştirilmiş ve Avusturalya, Avrupa, Amerika ve Uzakdoğu'da birçok kültüre uyarlanarak kültürler arası karşılaştırmalı çalışmalarda kullanılmış olan (Ganotice ve diğerleri, 2012; King ve diğerleri, 2012; McInerney ve Sinclair, 1991; Suliman ve McInerney, 2006) "Okula Yönelik Güdü Envanteri"nin Türkçeye uyarlanması amaçlanmaktadır.

Türkiye'deki alanyazına bakıldığında, okul güdüsünü ölçmeye yönelik bazı çalışmaların olduğu görülmektedir (Aktaş, 2009; Altun, 2010; Yavuz, 2006). Yavuz (2006) yüksek lisans tezinde okul güdüsü ölçeği geliştirmiş, hem Aktaş (2009), hem de Altun (2010) bu ölçme aracını kullanmışlardır. İlkokul yedinci sınıf öğrencileri üzerinde geliştirilmiş olan ölçek tek boyutlu bir yapı sunmaktadır. Öte yandan uluslararası alanyazında sıklıkla kullanılan (Ganotice ve diğerleri, 2012; King ve diğerleri, 2012; Lee, Ning ve Goh, 2014; McInerney, Roche, McInerney ve Marsh, 1997; Nasser ve McInerney, 2016; Watkins, McInerney ve Lee, 2002). Okula Yönelik Güdü Envanteri ise sekiz faktörlü bir yapıdadır. Ayrıca Yavuz'un (2006) ilköğretim öğrencileri için geliştirmiş olduğu okul güdüsünü ölçmeyi amaçlayan ölçeğin lisans öğrencileri için kullanılabilir olduğuna dair bir kanıt sunulmamıştır. Dolayısıyla ulusal alanyazınında lisans öğrencilerinin okula yönelik güdülerini ölçebilecek geçerli ve güvenilir ölçme araçlarına ihtiyaç duyulmaktadır.

\section{İlgili Alanyazın}

İnsanların ya da diğer canlıların neden belli durumlarda belli hareketleri başlattığı ve sürdürdüğü, neden o davranışı değil de diğerini gösterdiği yüzyıllardır araştırmacıların ilgisini çekmiş, bu konuda farklı açıklamalar yapılmıştır (Açıkgöz, 2003; Maehr, 1984; Wong, 2000). Davranışın birçok nedeni olmakla birlikte güdüyle ilgili nedenler oldukça önemli bir yere sahiptir (Açıkgöz, 2003; Wong, 2000). Latince hareket kelimesinden türemiş olan güdü terimi bizi harekete geçiren, çalışmaya devam etmemizi sağlayan ve bir görevi tamamlamamıza yardım eden güç olarak tanımlanabilir (Schunk ve diğerleri, 2008). Günümüzde güdü, onu 
harekete geçiren içsel güçler, uyarana verilen tepkiler, kendini verme, zaman ayırma, hoşlanma gibi pek çok duyguyu da içeren karmaşık yapılı bir özellik olarak tanımlanmaktadır (Açıköz, 2003; Schunk ve diğerleri, 2008). Güdünün başlıca göstergeleri seçme, beklememe, yoğunluk, kararlılık ve duygudur. Birey güdülü olduğu konuyla ilgili eylemleri beklemeden, tereddüt etmeksizin seçer, o konu üzerinde kararlı ve yoğun bir şekilde çalışabilir. O etkinlikten önce ve sonra hissedilenler de güdünün önemli bir göstergesidir (Açıkgöz, 2003).

Güdünün göstergelerinden birisi de, herhangi bir seçenek olduğunda hangisinin tercih edildiğidir. Bireyler güdülendikleri eylemi daha çok tercih etmektedir. Tercihin yanı sıra çaba da güdü için önemli göstergelerden birisidir. Güdülenmiş öğrenciler konuları öğrenmek için daha çok bilişsel çaba harcarlar; bilginin organize edilmesi, öğrenme düzeyinin sorgulanması ve yeni öğrenilenler ile önceki bilgilerin ilişkilendirilmesi gibi daha üst düzey bilişsel stratejileri işe koşarlar (Pintrich, 2003; Schunk ve diğerleri, 2008). Güdünün bir diğer göstergesi etkinlik için harcanan zamandır (Açıkgöz, 2003; Schunk ve diğerleri, 2008). Güdülenen öğrenciler zorluklarla karşılaştıklarında da öğrenmek için çaba harcamaya devam ederler. Son olarak öğrencilerin başarısı da güdünün dolaylı göstergelerinden birisi olarak kabul edilir. Birçok araştırmacı başarı ile güdünün göstergelerinden olan seçme, çaba ve zaman ayırma arasında olumlu bir ilişki bulmuştur (Pintrich, 2003; Schunk ve diğerleri, 2008).

Okula yönelik güdü öğrencilerin öğrenme etkinliklerine katılma konusundaki istekliliklerini incelemek açısından oldukça önemlidir. Güdü öğrencilerin yeni bilgileri öğrenmelerini ve daha önce öğrendikleri becerileri uygulamalarını etkilemektedir. Öğrenmeyle ilgili etkinliklerde güdü neyi, ne zaman ve nasıl öğreneceğimizi belirleyebilir (Schunk ve diğerleri, 2008). Öğrenciler okula farklı amaçlarla gelmektedir. Bu amaçlardan bazıları beceri ve yeteneklerini geliştirmek, daha başarılı olmak ve zeki olduklarını kanıtlamak, arkadaşlarıyla birlikte olmak, son olarak da çabaları karşılığında ödül ve pekiştireç almak olarak sıralanabilir (King ve diğerleri, 2012; Suliman ve McInerney, 2006). Öğrencilerin okula geliş amaçları okul ortamındaki akademik başarılarını, akademik çalışmalara katılım durumlarını, öğrenme stratejilerini, öz-yönelimli öğrenme etkinliklerini, genel iyi oluş hallerini ve eğitimle ilgili diğer birçok çıktıyı yakından etkilemektedir (King ve diğerleri, 2012; Maehr, 1984; Pintrich, 2000). $\mathrm{Bu}$ nedenle öğrencilerin okula yönelik güdülerinin belirlenmesi, okula geliş amaçları ve öğrenmeyle ilgili etkinliklere yönelik bakış açılarını anlamak açısından önemlidir.

Uluslararası alanyazında okula yönelik güdünün boyutları ve bunların başarı, bir üst kurumda eğitime devam etme planı gibi değişkenleri nasıl etkilediğini inceleyen birçok araştırmada Okula Yönelik Güdü Envanterinin (OYGE) işe koşulduğu görülmektedir (Ganotice ve diğerleri, 2012; Ho ve Hau, 2008; King ve diğerleri, 2012; Lee ve diğerleri, 2014; McInerney, 2008; Nasser ve McInerney, 2016; Suliman ve McInerney, 2006; Xu ve Barnes, 2011). Bu çalışmaların birçoğu ortaokul ve liseye devam etmekte olan öğrenciler üzerinde yürütülmüş olap bazıları da doğu ve batı kültürlerinde lisans öğrnecilerinin okula yönelik tutumlarını incelemeyi amaçlamıştır. King ve diğerleri (2012) bir görevi yerine getirmek için güdülenen öğrencilerin derinlemesine öğrenme stratejilerini daha çok işe koştukları, yüzeysel öğrenme stratejilerini daha az işe koştuklarını belirlemiştir.Ancak ödül gibi dışsal amaçlar için güdülenen öğrencilerin yüzeysel öğrenme stratejilerini işe koşma eğiliminde olduğu görülmektedir.

McInerney (2008) okula yönelik güdüsü görev yönelimli olan öğrencilerin hem okula devam oranlarının hem de okul başarılarının daha yüksek olduğunu belirtmektedir. Ayrıca bu öğrenciler bir üst öğrenime devam etmeye daha isteklidir ve okula daha çok değer vermektedirler. Görev yönelimli öğrencilerin akranlarını daha çok desteklediklerini de belirtmektedir. Dışsal güdülenmiş olan öğrencilerin başarıları ise oldukça düşüktür. Okul başarısı benlik algısıyla da doğrudan ilişkilidir. İşbirliği ve sosyal alaka azaldıkça hem okula yönelik güdü olumsuz etkilenmekte, hem de akademik başarı düşmektedir. Benlik algısı, başarı amaçları ve kişisel koşullar okula yönelik güdü üzerinde önemli etkiye sahip olan değişkenlerdir. Ayrıca okula yönelik görevleri kendi başlarına yerine getiren yani ebeveynlerinden yardım almayan öğrencilerin okulu daha çok sevdikleri görülmektedir. 
Lee ve diğerleri (2014) öğrencilerin okula yönelik güdüleri ile hafizaları ve matematik başarıları arasındaki ilişkiyi incelemiştir. Hem uzmanlık, hem de performansa (ego) yönelik güdüler öğrencilerin akademik başarılarına katkı sağlamaktadır. Ancak uzmanlığa yönelik güdünün katkısının daha yüksek olduğu görülmektedir. Performansa yönelik güdüsü yüksek olan öğrencilerin akademik başarıları daha düşüktür. Her iki güdü türü de çalışan hafiza kapasitesine katkı sağlamaktadır. Ancak uzmanlığa yönelik güdüsü daha yüksek olan öğrencilerin çalışan hafıza kapasiteleri de daha fazladır. Çalışan hafıza kapasitesi de matematik başarısı ile yüksek düzeyde ilişkilidir.

McInerney (2008) okula yönelik güdü ile okuldaki iyi oluş hali arasındaki ilişkiyi irdelemiştir. Performans, sosyal ve dışsal güdünün okuldaki iyi oluş hali üzerinde etkisi anlamlı değilken, görev amaçlı güdünün okuldaki iyi oluş halini olumlu etkilediği görülmektedir. Görev amaçlı güdünün aynı zamanda notlar, sonraki eğitim hayatına devam etme ve okulu değerli bulma üzerinde güçlü etkileri bulunmaktayken; performans, sosyal ve dişsal güdüler bu değişkenler için oldukça zayıf bir etkiye sahiptir (McInerney, 2008). McInerney ve Sinclair (1991) Avustralya'daki öğrencilerin liseyi bitirme eğilimleri üzerinde en güçlü etkiye sahip değişkenin görev eğilimi olduğunu belirtmektedir. Performans, sosyal ve dışsal güdü de liseyi bitirme eğilimini olumlu etkilese de bunların etkisi görev eğilimine göre epey düşüktür (King ve diğerleri, 2012; McInerney ve Sinclair, 1991). Suliman ve McInerney (2006) Avustralya'da öğrenim gören Lübnan kökenli öğrencilerinin okul başarıları ile temel güdü kaynaklarını incelemiştir. Araştırmada öğrencilerin başarılarını okul güdüsünün sosyal kaygı, fark edilme isteği ve ödül beklentisi faktörlerini daha çok etkilediği görülmektedir.

Batı toplumlarında yapılan araştırmalarda OYGÖ'nin faktörlerinin birbiriyle düşük düzeyde ilişkili olduğu, okula yönelik güdünün bağımlı değişkenleri farklı oranlarda etkilediği görülmekte iken, doğu toplumlarında yapılan çalışmalarda ise OYGÖ’nin faktörlerinin birbiri ile yüksek derecede ilişkili olduğu bulunmuştur (Elliot ve Murayama, 2008; King ve diğerleri, 2012). Başka bir değişle doğu toplumlarında görev, performans, sosyal dayanışma ve dışsal pekiştireç faktörleri birbiriyle yüksek derecede ilişkili iken, bu ilişki batı toplumlarında yapılan çalışmalarda ya çok düşük düzeydedir ya da anlamsızdır (Elliot ve Murayama, 2008; King ve diğerleri, 2012; Miller, Greene, Montalvo, Ravindran ve Nichols, 1996). Bat1 ve doğu toplumları arasında başarı, güdü ve öğrenme arasındaki ilişkinin doğu toplumlarında aynı şekilde ortaya çıkmaması kültürel farklarla açıklanmaktadır (Ho ve Hau, 2008).

Bireylerin davranışlarını belirlemede etkili olan birçok psikolojik özellik bulunmaktadır. Güdünün yanı sıra tutumlar da davranışın belirleyicisi olan önemli psikolojik özelliklerdendir. Tutumlar herhangi bir psikolojik objeye yönelik olumlu olumsuz yönelimler olarak ele alınabilir ve bilişsel, duyuşsal ve psikomor olmak üzere üç faktörlü olduğu belirtilmektedir (Eagly ve Chaiken, 2007; Gürün, 1991). Alanyazında ki birçok araştırmada tutumlar ile güdü arasında anlamlı bir ilişki olduğu görülmektedir (Ayna, 2009; Jain ve Sidhu, 2013; Türel, 2008). Türel (2008) öğrenme nesneleri ile zenginleştirilmiş öğrenme ortamının hem tutumları hem de güdüye etkisini incelemiş, tutum ve güdünün birlikte değiştiğini belirtmiştir. Jain ve Sidhu (2013) ikinci dil olarak İngilizce öğrenmekte olan öğrencilerin güdüleri ve tutumları arasında anlamlı bir ilişki olduğunu belirtmektedir. Erten (2015) ise güdü ve tutumu birlikte ele almış ancak birlikte değişmediklerini dile getirmiştir.

Davranışın belirleyicisi olan başka bir psikolojik özellik algılanan öz yeterliktir. Bireylerin öz yeterlik algıları yükseldikçe ilgili alanda eyleme geçme ihtimalleri artmaktadır (Bandura, 1977). Benzer bir şekilde Salomon (1984) da öz yeterlik arttıkça çabanın arttı̆̆ını belirtmiş̧tir. Güdü ile öz yeterlik arasında ilişki olduğunu belirten birçok araştırma bulunmaktadır (Greene, Miller, Crowson, Duke ve Akey, 2004; McInerney, 2008; Miller ve diğerleri, 1996; Raposo, Rico ve Castro, 2017; Wang, Li ve Hsieh, 2013). Kendilerine güvenen ve kendilerini yeterli gören öğrencilerin güdüleri de daha yüksek olmaktadır (Schunk ve diğerleri, 2008). Greene, Miller, Crowson, Duke ve Akey’e (2004) göre hem güdü hem de öz yeterlik algıları öğrencilerin başarısı üzerinde dolaylı ve doğrudan etkiye sahiptir. 
McInerney (2008) benlik algısı ile okula yönelik güdü ve okul başarısı arasında olumlu bir ilişki olduğunu belirtmektedir. Bununla birlikte Miller ve diğerleri (1996) algilanan yeterlik ile okula yönelik güdü arasında pozitif bir ilişki olduğunu dile getirmiştir. Ayrıca Fan, Wang ve Wang (2011) algılanan öz yeterlik ve içsel güdünün üretkenlik ve başarı üzerinde birlikte anlamlı bir ilişkiye sahip olduklarını belirtmektedir. Raposo, Rico ve Castro (2017) ise matematik öğrenen bireyler üzerinde yaptıkları incelemelerde öğrencilerin güdüleri arttıkça öz yeterliklerinin bundan olumlu olarak etkilendiğini bulmuştur. Ayrıca Akyol (2016) öğretmen adaylarının öğrenmeye yönelik güdüleri ve mesleki öz yeterlik algıları arasında anlamlı bir ilişki olduğunu belirtmektedir. Bunlara karşın Ersanlı (2015) ise öğrencilerin akademik öz yeterlikleri ile İngilizce öğrenmeye yönelik güdüleri arasında anlamlı bir ilişki olmadığını dile getirmektedir.

Okula Yönelik Güdü Envanterinin alanyazında birçok kültüre uyarlandığı, kültürler arası karşılaştırmalı çalışmalarda kullanıldığı, ortaokul, lise ve üniversite öğrencileri için geçerliği ve güvenirliğinin incelendiği görülmektedir (King ve diğerleri, 2012; McInerney ve Sinclair, 1991; Xu ve Barnes, 2011). Bu nedenle ölçeğin Türkçe’ye uyarlanması hem ulusal alanyazınına hem de uluslararası alanyazına önemli katkılar getirebilir. Öğrencilerin okula yönelik güdü envanteri ile ilgili faktörlerin incelenmesi okula gelme güdülerini daha ayrıntılı anlamaya ve ögrenme sürecini desteklemek amacıyla ne gibi tedbirler alınması gerektiğine $1 s ̧ 1 k$ tutabilir (Lee ve diğerleri, 2014; Suliman ve McInerney, 2006). Ayrıca öğrencilerin okula yönelik güdüleri üzerinde etkili olan değişkenlerle ilişkilerini analiz etmek de mümkün olacaktır. Türkiye'de okula yönelik güdü ve bunu etkileyen değişkenlerin incelenmesinin yanı sıra Türk kültürü ile farklı kültürler arası karşılaştırmalı çalışmalar yürütülerek uluslar arası alanda okula yönelik güdünün anlaşılmasına katk1 sağlanabilecektir. Bununla birlikte birçok araştırma hem tutumun hem de öz yeterliğin güdü ile ilişkili olduğunu belirtmektedir (ör. Ayna, 2009; Greene ve diğerleri, 2004; Jain ve Sidhu, 2013; Raposo ve diğerleri, 2017). Bu araştırmaların çoğunlukla yurt dışı odaklı olduğu Türkiye'de güdünün özellikle öz-yeterlik ile ilişkisini inceleyen çalışma sayısının sınırlı olduğu görülmektedir (Greene ve diğerleri, 2004; McInerney, 2008; Miller ve diğerleri, 1996; Raposo ve diğerleri, 2017; Wang ve diğerleri, 2013). Bu araştırma okula yönelik güdü ile okula yönelik tutum ve genel öz yeterlik arasındaki ilişkinin incelenmesi bakımından ulusal alanyazına katkı sunulabilir. Bununla birlikte alanyazında güdü, tutum ve öz yeterlik arasındaki ilişkiyi birlikte ele alan bir çalışmaya rastlanmamıştır. $\mathrm{Bu}$ araştırmanın bahsedilen üç değişken arasındaki ilişkinin birlikte ele alınması bakımından da özgünlük taşıdı̆̆ı söylenebilir.

\section{Yöntem}

Var olan durumun ortaya çıkarılmasını amaçlayın bu çalışmada, betimsel yöntem kullanılmıştır. Araştırma grubunu Ege Üniversitesinde öğrenim görmekte olan Eğitim Fakültesi öğrencileri ile Pedagojik Formasyon Sertifika programına devam etmekte olan toplam 1336 lisans ögrencisi oluşturmaktadır. Söz konusu öğrenciler araştırmaya seçkisiz yöntemle dahil edilmiştir. OYGÖ'nin çeviri çalışmaları sonucu elde edilen Türkçe formu ilk uygulamada 552, ikinci uygulamada 784 olmak üzere toplam 1336 öğrenciye uygulanmıştır. İlk uygulamaya tarih, sosyoloji vb. sözel alandan 89, halka ilişkilerden 105, matematik, fizik, kimya gibi temel bilimlerden 56, mühendislik fakültesinden 64 , sağlık bilimlerinden 56 , spor bilimlerinden 50 ve dil alanından 66 öğrenci katılmıştır. İkinci uygulamaya ise dil alanından 57, spor bilimlerinden 24, sağlık bilimelrinden 74, matematik, fizik, kimya gibi temel bilimlerden 94, bilgisayar öğretmenliğinden 43 , fen bilgisi öğretmenliğinden 48 , halka ilişkilerden 49 , güzel sanatlardan 31, rehberlik ve psikolojik danışmanlıktan 84 , psikoloji ve felsefe bölümlerinden 37 , sınıf ögretmenliğinden 33, sosyoloji, tarih gibi sosyal bilimler alanından 47, Türkçe öğretmenliğinden ise 136 kişi katılmıştır. Bazı katılımcılar ise bölümlerini belirtmeden ölçekleri doldurmuştur. İlk uygulamya katılan öğrencilerin 352si cinsiyetini katın, 183ü erkek olarak belirtmiş, 17 katılımcı cinsiyetini belirtmemiştir. İkinci uygulamada ise katılımcıların 561'i cinsiyetini kadın, 201'i erkek olarak belirtmiş, 22 katılımcı cinsiyetini belirtmemiştir. 


\section{Veri toplama araçları}

\section{Okula Yönelik Güdü Envanteri}

Bu araştırma kapsamında McInerney ve Sinclair (1991) tarafından geliştirilmiş olan OYGÖ'nin Türkçeye uyarlama çalışması yürütülmüştür. Ölçek 43 maddeden oluşmakta olup görev, performans, sosyal dayanışma ve dişsal pekiştireç olmak üzere dört boyut her boyutun altında iki faktör olmak üzere toplam sekiz faktörden oluşmaktadır. Bu faktörler de sırasıyla görev yönelimi (maddeler 1-4), çaba (maddeler 5-11) yarışma (maddeler 12-17) sosyal güç (maddeler 18-23), işbirliği (meddeler 24-26), sosyal alaka (maddeler 27-31), övgü (maddeler 32-36) ve ödül (maddeler 37-43) olarak isimlendirilmiştir. Üstte belirtilen dört boyut ve sekiz faktörden oluşan ölçme aracının geliştirilmesi sırasında Maehr'in (1984) Kişisel Yatırım Kuramı temel alınmıştır. Araştırmacılar ölçme aracını Aborjin, İngiliz ve Göçmenler olmak üzere üç farklı kültürde işe koşmuşlar ve kültürler arası kullanılabilir olduğunu belirtmişlerdir. Araştırmaya yedinci sınıfla onuncu sınıf arasındaki öğrenciler katılmıştır (McInerney ve Sinclair, 1991). Orijinal ölçeğin doğrulayıcı faktör analizi sonuçlarına göre, kurulan modelin veri uyumunun kabul edilebilir sınırlar içinde olduğu belirtilmiş (CFI $\geq .90$, RMSEA $\leq .10$, ve SRMR $\leq$ yaklaşık olarak .08.), İngilizce uygulanan versiyonu için Cronbach alpha güvenirlik katsayıları .70 ile .85 arasında hesaplanmıştır (McInerney ve Sinclair, 1991; Xu ve Barnes, 2011). Okula yönelik güdü envanteri birçok araştırmacı tarafindan farklı kültürlere uyarlanmış ve kültürler aras1 çalışmalarda da kullanılmıştır (Ganotice ve diğerleri, 2012; King ve diğerleri, 2012; Watkins ve diğerleri, 2002; Watkins, McInerney ve Akande, 2003; Xu ve Barnes, 2011). Ölçeğin ilk formu ortaokul ve lise öğrencileri için geliştirilmiş olsa da daha sonra hem Çin hem de Amerikada ki lisans öğrnecileri için de kullanılabilir olduğu belirtilmiştir (Xu ve Barnes, 2011). Bu araştırmalardan bazıları Avustralya'da Aborjinlerin ve göçmenlerin de katıldığ araştırmalar (McInerney, 2008; McInerney ve Sinclair, 1991), Hong Hong ve Filipinlerde yürütülen çalışmalar (King ve diğerleri, 2012), Güney Afrika'da yürütülen araştırmalar (Watkins ve diğerleri, 2003), Amerikalı ve Çinli öğrencilerin katıldığı araştırmalar olarak listelenebilir (Xu ve Barnes, 2011).

OYGÖ'nin Türkçeye uyarlanması için ilk olarak üç uzman tarafindan orijinal ölçek Türkçeye çevrilmiş ve üç Türkçe çeviri elde edilmiştir. Daha sonra başka üç uzman tarafından Türkçe formlar ayrı ayrı İngilizceye çevrilmiştir. Araştırmacı ve çeviri sürecine katılmayan bir dil uzmanı tarafından üç ayrı çeviri incelenmiş, orijinaline en yakın maddeler seçilerek Türkçe form oluşturulmuştur. Daha sonra oluşturulan form çeviri sürecine katılmayan iki dil uzmanı, altı akademisyen ve altı lisans öğrencisine uzman görüşü alınmak amacıyla sunulmuştur. Uzman görüşleri doğrultusunda bazı güncellemeler yapılarak Türkçe form son şekline getirilmiştir. Beşli likert tipindeki ölçek "Kesinlikle Katılmıyorum", "Kesinlikle Katılıyorum”a doğru sıralanan beş seçenek sunmaktadır. Ölçeğin Türkçe formunun deneme uygulamaları aşamasına geçilmiştir.

\section{Okula Yönelik Tutum Ölçeği}

Okula yönelik tutum ölçeği Alıcı (2013) tarafından geliştirilmiştir ve psikometrik özellikleri lise öğrencileri için incelenmiştir. Yirmi maddeden oluşan ölçek üç bileşene sahiptir. Bu bileşenler "Kişisel Gelişimin Engeli Olarak Okul", "Kişisel Gelişimin Destekleyicisi Olarak Okul”, ve "Özlenen Bir Varlık Olarak Okul” olarak adlandırılmıştır. Beşli likert tipindeki ölçek "Kesinlikle Katılmıyorum", "Kesinlikle Katılıyorum"a doğru sıralanan beş seçenekli olarak uygulanmıştır. Ölçeğin bütününe ve alt bileşenlerine ilişkin Cronbach Alpha güvenirliği sırasıyla $0.91 ; 0.87 ; 0.81$ ve 0.79 olarak bulunmuştur. Doğrulayıcı faktör analizi sonuçlarında da ölçeğin veri uyumunun kabul edilebilir sınırlar içerisinde olduğu görülmektedir. Bu araştırmada ölçeğin psikometrik özelliklerinin lisans öğrencileri için de geçerli olup olmadığı incelenmiştir. 771 lisans öğrencisinden elde edilen veriler 1şı̆̆ında işe koşulan doğrulayıcı faktör analizi sonucu ölçeğin lisans öğrencileri için de kullanılabilir olduğu görülmüştür (RMSEA: .074, CFI: .91, SRMR: .049). Doğrulayıc1 faktör analizinde elde edilen standardize sonuçlar Şekil 1'de sunulmuştur. 


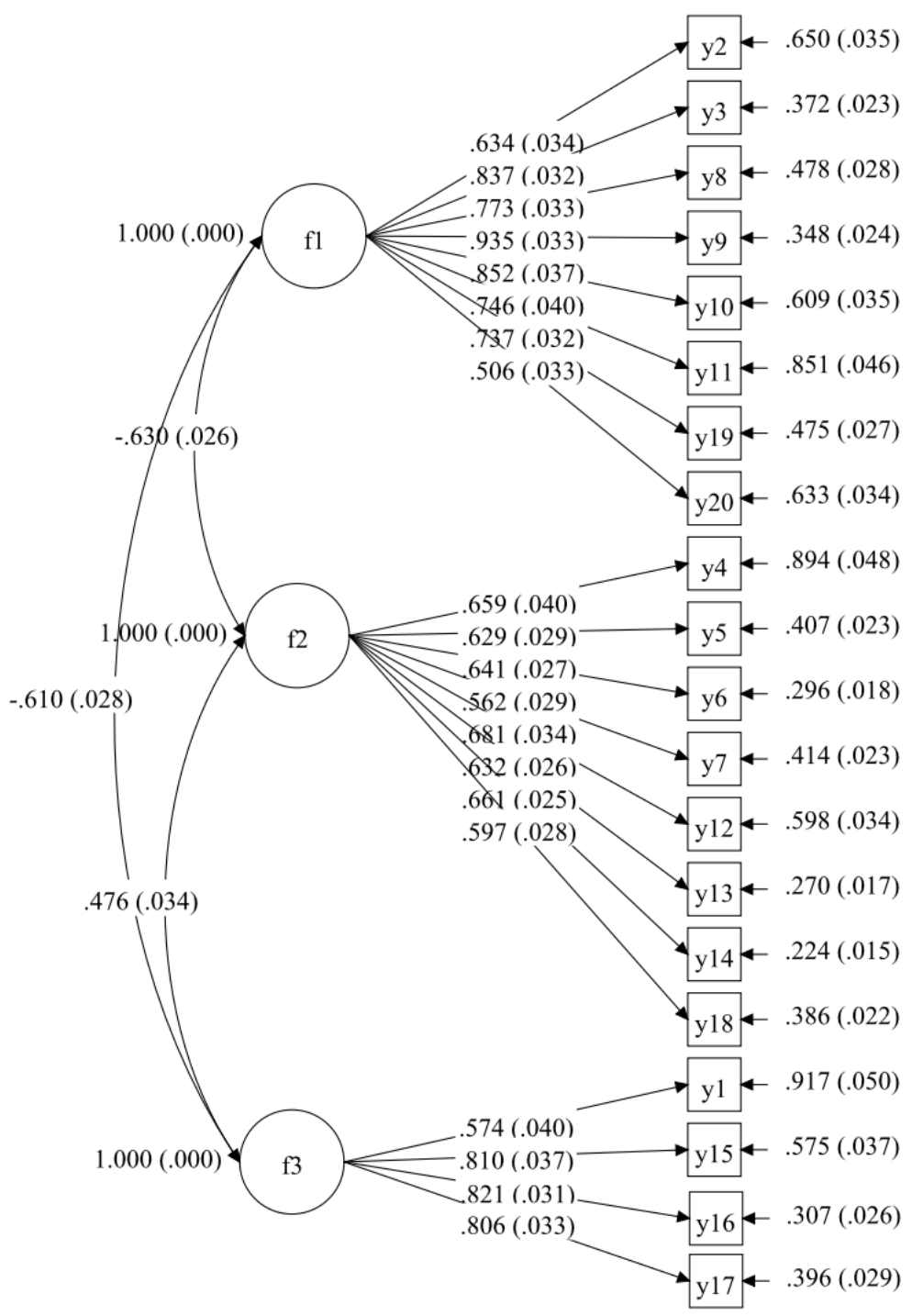

Şekil 1. Okula Yönelik Tutum Ölçeği'nin lisans öğrencileri için elde edilen DFA sonuçları (Standardize sonuçlar)

\section{Genel Öz Yeterlik Ölçeği}

Genel öz yeterlik ölçeği ise Aypay (2010) tarafından Türkçeye uyarlanmıştır. Uyarlama çalışmaları üç farklı üniversiteden toplam 693 öğrenci üzerinde yürütülmüştür. Uyarlama çalışmaları sonucunda 10 maddeden oluşan ölçek iki faktörden oluşmakta ve toplam varyansın \%47'sini açıklamaktadır. İlk faktör "çaba ve direnç", ikinci faktör ise "yetenek ve güven" olarak isimlendirilmiştir. Maddelerin faktör yük değerleri .45 ila .79 arasında değişmektedir. Dört seçenek olarak uygulanan ölçek "Tamamen Yanlış", "Çoğunlukla Yanlış", "Çoğunlukla Doğru" ve "Tamamen Doğru" seçeneklerini barındırmaktadır. Bu uygulamadaki Cronboch Alpha iç tutarlık güvenirlik katsayıları faktörler için sırasıyla .72 ve .85 , ölçeğin tamamına ilişkin ise .88 olarak hesaplanmıştır.

\section{Verilerin toplanması}

Okula Yönelik Güdü Envanterinin Türkçe'ye çevirme işlemleri tamamlandıktan sonra orijinal faktör yapısının Türkçe form içinde geçerli olup olmadığının incelenmesi amacıyla 554 lisans öğrencisine uygulanmıştır. Daha sonra ölçüt geçerliliğinin incelenmesi amacıyla çevirisi yapılan 
OYGÖ, Okula Yönelik Tutum Ölçeği ve Genel Öz Yeterlik Ölçeği ilk uygulamaya katılmayın 784 lisans öğrencisine uygulanmıştır.

\section{Verilerin analizi}

Ölçeğin orijinal kültürdeki faktöriyel yapısına sadık kalınarak bir DFA model kurulmuş ve bu model örneklemden elde edilen veriler ile Mplus 7.4 yazılımı kullanılarak test edilmiştir. Analiz öncesinde incelenen çarpıklık ve basıklık değerleri $+1 /-1$ aralığında değiştiğinden, normal dağılım varsayımının karşılandığı sonucuna varılmıştır. OYGÖ, okula yönelik tutum ve genel öz yeterlik arasındaki ilişki de yol analizi yöntemiyle incelenmiştir.

\section{Bulgular}

Okula Yönelik Güdü Envanterinin Türkçe formunun geçerlik ve güvenirliğine ilişkin bulgular ölçme aracının geçerliği ve güvenirliği şeklinde iki tamal başlık altında sunulmuştur.

\section{Geçerlik}

Okula Güdü Ölçeğinin sekiz faktörlü yapısı alanyazında kabul görmüş ve birçok kültüre de uyarlanmıştır ve diğerleri, 2012; King ve diğerleri, 2012; McInerney ve Sinclair, 1991; Xu ve Barnes, 2011). Bu nedenle araştırmada geçerlik açısından ilk olarak birçok kültürde kabul görmüş olan bu sekiz faktörlü yapının Türk kültürü için de geçerli olup olmadığı Doğrulayıcı Faktör Analizi ile incelenmiştir. Elde edilen uyum indeksleri RMSEA:.068, CFI:.86, SRMR: .084 olarak hesaplanmıştır. Maddelere ilişkin standart katsayıları ile modelin sonuçları Tablo 1 'de sunulmuştur.

Tablo 1.

Standart Katsayıları ile Modelin Sonuçları

\begin{tabular}{llllll}
\hline & & Tahminleme & $\begin{array}{l}\text { Standart } \\
\text { Hata }\end{array}$ & Tah../S.H & $\begin{array}{c}\text { P-Değerleri } \\
\text { (2 Yönlü) }\end{array}$ \\
\hline F1 & M1 & 0.729 & 0.024 & 30.541 & 0.000 \\
yörevelimi & M2 & 0.839 & 0.016 & 51.316 & 0.000 \\
& M3 & 0.901 & 0.012 & 74.258 & 0.000 \\
& M4 & 0.884 & 0.013 & 66.310 & 0.000 \\
\hline F2 & M5 & 0.568 & 0.035 & 16.255 & 0.000 \\
Çaba & M6 & 0.778 & 0.023 & 33.763 & 0.000 \\
& M7 & 0.709 & 0.026 & 26.749 & 0.000 \\
& M8 & 0.490 & 0.038 & 12.764 & 0.000 \\
& M9 & 0.567 & 0.036 & 15.706 & 0.000 \\
& M10 & 0.729 & 0.026 & 28.396 & 0.000 \\
& M11 & 0.777 & 0.023 & 33.515 & 0.000 \\
F3 & & & & & \\
Yar1şma, & M12 & 0.515 & 0.037 & 13.931 & 0.000 \\
& M13 & 0.746 & 0.024 & 31.555 & 0.000 \\
& M14 & 0.820 & 0.019 & 44.329 & 0.000 \\
& M15 & 0.767 & 0.022 & 34.336 & 0.000 \\
& M16 & 0.819 & 0.019 & 43.419 & 0.000 \\
F4 & M17 & 0.638 & 0.030 & 21.060 & 0.000 \\
Sosyal güç & M18 & 0.798 & 0.020 & 40.442 & 0.000 \\
& M19 & 0.445 & 0.040 & 11.171 & 0.000 \\
& M20 & 0.757 & 0.023 & 33.202 & 0.000 \\
& M21 & 0.870 & 0.015 & 57.935 & 0.000 \\
& M22 & 0.767 & 0.022 & 34.666 & 0.000 \\
& M23 & 0.787 & 0.021 & 38.171 & 0.000 \\
\hline
\end{tabular}




\begin{tabular}{llllll}
\hline F5 & M24 & 0.771 & 0.024 & 31.551 & 0.000 \\
İşbirliği & M25 & 0.894 & 0.021 & 43.520 & 0.000 \\
& M26 & 0.711 & 0.028 & 25.375 & 0.000 \\
\hline F6 & M27 & 0.775 & 0.023 & 34.401 & 0.000 \\
Sosyal alaka & M28 & 0.824 & 0.019 & 42.326 & 0.000 \\
& M29 & 0.764 & 0.023 & 33.030 & 0.000 \\
& M30 & 0.712 & 0.026 & 26.931 & 0.000 \\
& M31 & 0.557 & 0.035 & 15.764 & 0.000 \\
\hline F7 & M32 & 0.836 & 0.017 & 49.514 & 0.000 \\
Övgü & M33 & 0.887 & 0.014 & 65.383 & 0.000 \\
& M34 & 0.769 & 0.022 & 35.680 & 0.000 \\
& M35 & 0.761 & 0.022 & 34.356 & 0.000 \\
& M36 & 0.723 & 0.024 & 29.557 & 0.000 \\
\hline F8 & M37 & 0.816 & 0.018 & 45.012 & 0.000 \\
Ödül & M38 & 0.819 & 0.018 & 45.820 & 0.000 \\
& M39 & 0.797 & 0.019 & 41.157 & 0.000 \\
& M40 & 0.822 & 0.018 & 46.495 & 0.000 \\
& M41 & 0.728 & 0.024 & 30.267 & 0.000 \\
& M42 & 0.644 & 0.030 & 21.789 & 0.000 \\
& M43 & 0.641 & 0.030 & 21.630 & 0.000 \\
\hline
\end{tabular}

Elde edilen sonuçlara ilişkin standartize sonuçları gösteren grafik ise Şekil 2'de sunulmuştur. 


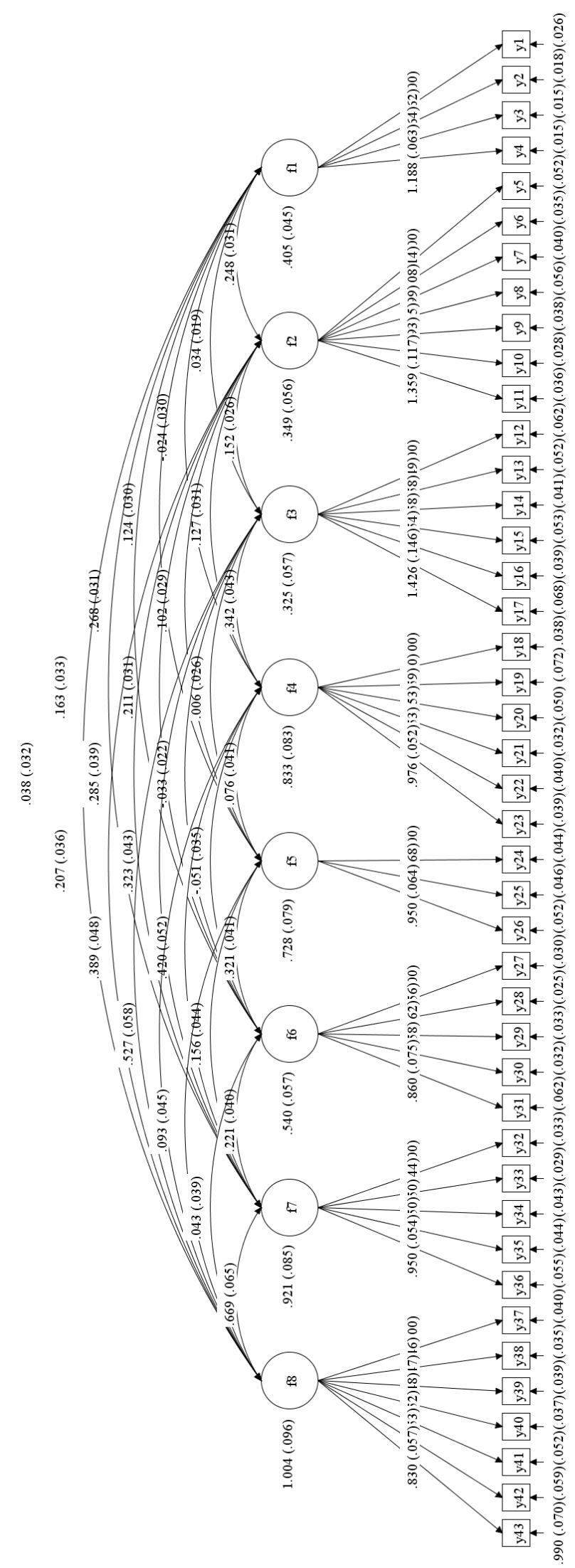

Şekil 2. Doğrulayıcı Faktör Analizine İlişkin Standardize Sonuçlar 
Elde edilen Okula Yönelik Güdü Envanterinin Türkçe versiyonunun geçerlik çalışmaları kapsamında ikinci olarak ölçüt geçerliliğinin incelenmesi amacıyla benzer yapıdaki ölçme araçları ile aralarındaki korelasyon araştırılmıştır. Bu amaçla Okula Yönelik Tutum ve Genel Öz Yeterlik ölçekleri ile Okula Yönelik Güdü Envanteri arasındaki ilişki hesaplanmıştır. Üç değişken arasındaki ilişki yapısal eşitlik modeliyle incelenmiş olup modele ilişkin uyum indeksleri RMSEA:.072, GFI:.94, AGFI..91, NFI..91 olarak hesaplanmıştır. Bu durumda kurulan modelin veri uyumunun kabul edilebilir düzeyde olduğu görülmektedir. Analizler sonucu elde edilen standardize katsayılar Şekil 3'de, pathlere ait t-değerleri ise Şekil 4'de sunulmuştur. Değerlerde görüldüğü gibi model tarafindan tahminlenen path katsayıları istatistiksel olarak anlamlı bulunmuştur. Başka bir ifadeyle Okula Yönelik Güdü Envanteri, Okula Yönelik Tutum ve Genel Öz Yeterlik ölçekleriyle anlamlı ilişkilere sahiptir.

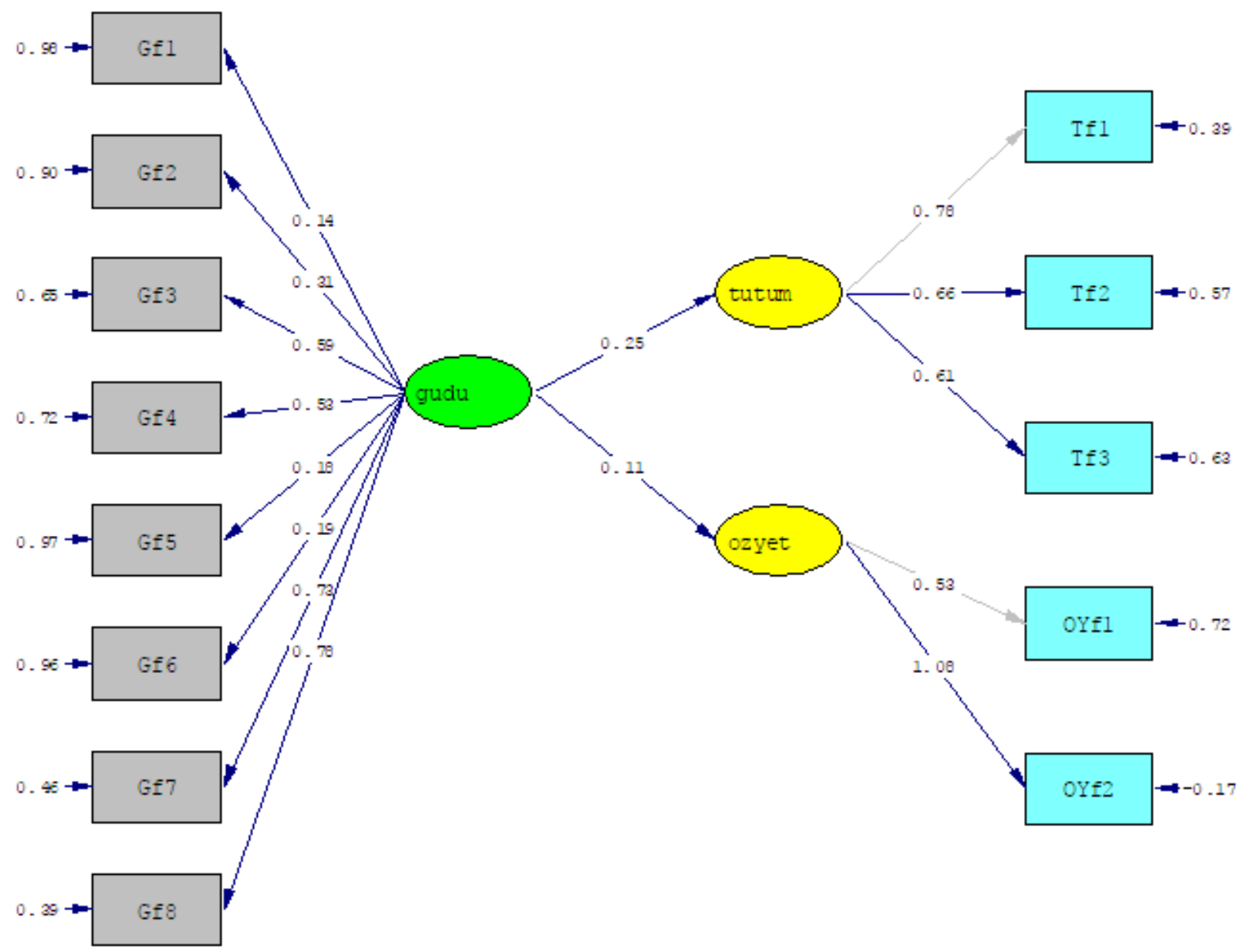

Chi-3quare $=293.41$, df $=58, p-v a l u e=0.00000, \mathrm{RMSEA}=0.072$

Şekil 3. Okula Yönelik Tutum, Genel Öz Yeterlik ve Okul Güdü Ölçekleri Arası Korelasyon Modeline İliş̧kin Standardize Sonuçlar 


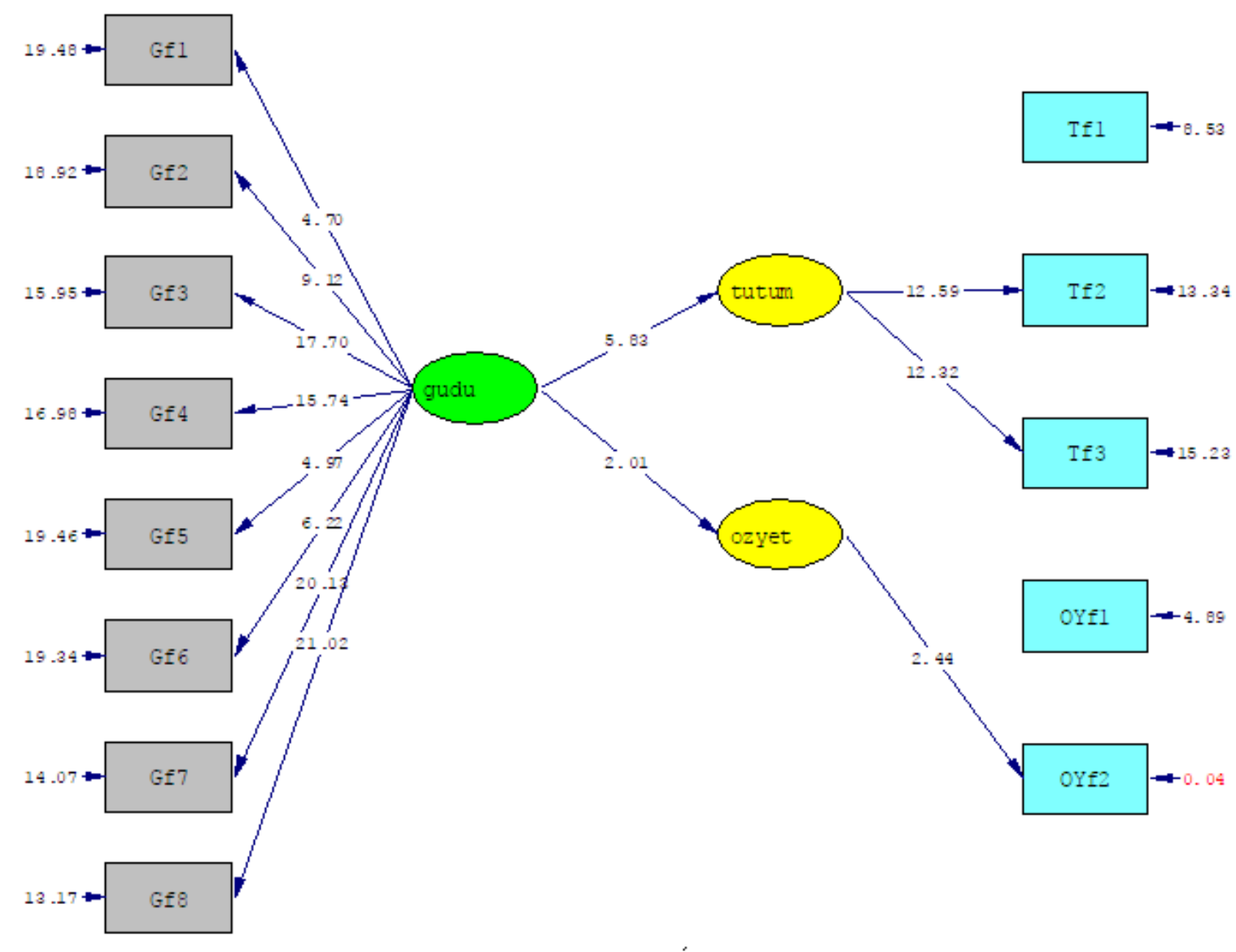

Şekil 4. Okula Yönelik Tutum, Genel Öz Yeterlik ve Okul Güdü Ölçekleri Arası Korelasyon Modeline İlişkin T-Değerleri

\section{Güvenirlik}

Okula yönelik güdü envanterinin güvenirlik hesaplamaları için Cronbach alpha iç tutarlılık katsayısı hesaplanmışkır. Ölçeğin faktörlerine ilişkin güvenirlik katsayıları görev yönelimi faktöründe .90 , çaba faktöründe. 84 , yarışma faktöründe. 87 , sosyal güç faktöründe .89 , işbirliği faktöründe .86 , sosyal alaka faktöründe .84 , övgü faktöründe .91 , son olarak da ödül faktöründe .93 olarak hesaplanmıştır.

\section{Sonuç, Tartıșma ve Öneriler}

$\mathrm{Bu}$ araştırmada Okula Yönelik Güdü Envanterinin Türkçeye çeviri çalışmaları yapılmış ve psikometrik özelliklerinin lisans öğrencileri için geçerli olup olmadığı incelenmiştir. Geçerlik incelemeleri amacıyla DFA ve ölçüt-bağıntılı geçerlik analiz edilmiştir. Güvenirlik için Cronmah-Alpha iç tutarlılık katsayıları hesaplanmıştır. Okula Yönelik Güdü Envanterinin orijinal faktör yapısının Türkçe form için de geçerli olup olmadığının incelenmesi için işe koşulan DFA sonucu elde edilen uyum iyilikleri (RMSEA: 0.068, CFI:0.86, SRMR:0.084) kabul edilebilir sınırlar içinde bulunmuştur (Jöreskog ve Sörbom, 1993; Şimşek, 2007).

Okula Yönelik Güdü Envanterinin Türkçe formunun ölçüt-bağıntılı geçerliliğini test etmek amacıyla benzer yapılardaki ölçme araçları ile aralarındaki korelasyon incelenmiştir. Alanyazında öğrencilerin güdülerinin, tutum ve öz yeterlik ile ilişkili olduğunu belirten birçok araştırma bulunmaktadır (Ayna, 2009; Greene ve diğerleri, 2004; Jain ve Sidhu, 2013; McInerney, 2008; Miller ve diğerleri, 1996; Raposo ve diğerleri, 2017; Türel, 2008). Bu nedenle 
OYGÖ’nin ölçüt geçerliliğinin test edilmesi için OYGÖ ile Okula Yönelik Tutum ve Genel ÖzYeterlik arasındaki ilişki irdelenmiştir. Bu amaçla kurulan yapısal eşitlik modelinde değişkenler arasındaki ilişkiler istatistiksel olarak anlamlı bulunmuştur. Bu durumda OYGÖ ile okula yönelik tutum ve genel öz yeterlik arasında istatistiksel olarak anlamlı bir ilişkinin bulunduğu söylenebilir. Alanyazında bu sonucu destekleyen birçok araştırma bulunmaktadır (Ayna, 2009; Greene ve diğerleri, 2004; Jain ve Sidhu, 2013; McInerney, 2008; Miller ve diğerleri, 1996; Raposo ve diğerleri, 2017; Türel, 2008). Türel (2008) yaptığı deneysel çalışmada tutum ve güdünün birlikte değiştiğini belirtmekte; Jain ve Sidhu (2013) ise tutum ve güdü arasında anlamlı bir ilişki bulunduğunu, bu ilişkinin alt başarı grubundaki öğrenciler için daha güçlü iken üst başarı grubundaki öğrenciler için daha zayıf olduğunu belirtmiştir. Bunlara karşın Erten (2015) ise tutum ve güdü arasında anlamlı bir ilişki olmadığını dile getirmiştir.

Tutumun yanı sıra güdü ile öz yeterlik arasında anlamlı bir ilişki olduğunu belirten birçok araştırma da bulunmaktadır (Greene ve diğerleri, 2004; McInerney, 2008; Miller ve diğerleri, 1996; Raposo ve diğerleri, 2017). Bireylerin öz yeterlik algıları geliştikçe harekete geçme ihtimalleri ve çabaları; dolayısıyla da güdüleri artmaktadır (Bandura, 1977; Salomon, 1984). Benzer bir şekilde Schunk ve diğerleri (2008) öz yeterlik algıları yüksek öğrencilerin güdülerinin de daha yüksek olduğunu belirtmektedir. Hem güdü hem de öz yeterlik algıları, öğrencilerin akademik başarıları üzerinde önemli etkiye sahip olan değişkenlerdir (Greene ve diğerleri, 2004). Benzer bir şekilde Raposo, Rico ve Castro (2017) da öğrencilerin güdüleri arttıkça algılanan öz yeterliklerinin de bu durumdan olumlu etkilendiğini belirtmektedir.

Ölçeğin faktörlerine ilişkin güvenirlik katsayılarının da yeterli olduğu bulunmuştur (Kalayc1, 2008). Bu durumda ölçeğin Türkçe formunun geçerli ve güvenilir olduğu sonucuna varılmıştır. Başka bir deyişle, orijinal ölçeğin sunduğu sekiz faktörlü yapının araştırmaya dahil edilen lisans öğrencileri düzeyiden Türk kültürü için de geçerli olduğu söylenebilir. Benzer bir şekilde McInerney ve Sinclair (1991) tarafindan geliştirilmiş olan OYGÖ’nin farklı birçok kültüre uyarlanmış olduğu ve kültürler arası karşılaştırmalı çalışmalarda kullanıldığ görülmektedir (Ganotice ve diğerleri, 2012; King ve diğerleri, 2012; Suliman ve McInerney, 2006; Xu ve Barnes, 2011). Xu ve Barnes (2011) ölçeğin sekiz faktörlü yapısının Amerikalı ve Çinli üniversite öğrencileri için de geçerli olduğunu belirtmiştir. Bununla birlikte Ganotice et al. (2012) OYGÖ’nin faktör yapısının hem İngilizce hem de Filipin dillerinde geçerli olduğunu belirtmektedir. King et al. (2012) ise ölçeği hem Hong Hong, hem de Filipin kültürlerinde geçerli bulmuştur. Suliman ve McInerney (2006) ise OYGÖ'nin Avustralya'da eğitim görmekte olan Lübnan kökenli öğrenciler için de kullanılabilir olduğunu belirtmektedir.

Okula Yönelik Güdü Envanteri 43 maddeden oluşmakta olup görev, performans, sosyal dayanışma ve dışsal pekiştireç olmak üzere dört boyut içermekte, her boyutun içinde iki faktör bulunmaktadır. Bu faktörler sırasıyla görev yönelimi, çaba, yarışma, sosyal güç, işbirliği, sosyal alaka, övgü, ve ödül olarak isimlendirilmiştir.

OYGÖ'nin ilk faktörü olan görev yönelimi, öğrencilerin bir görevi yerine getirmek için daha çok çaba harcama eğiliminde olduklarını belirtmektedir. Bu faktörde yüksek puan alan öğrenciler derinlemesine öğrenme stratejilerini daha çok işe koyarken, yüzeysel öğrenme stratejilerini daha az kullanmaktadır (King ve diğerleri, 2012). Öğrenme stratejilerinin yanı sıra görev yönelimli güdülenen öğrencilerin okuldaki iyi oluş hallerinin olumlu olduğu, daha yüksek notlara sahip oldukları ve okulu daha değerli bulmaktadır (McInerney, 2008; McInerney ve Sinclair, 1991). Ayrıca bu öğrenciler bir üst öğrenime devam etmeye daha isteklidir ve akranlarını daha çok desteklemektedir (McInerney, 2008). McInerney ve Sinclair (1991) Avustralya'daki öğrencilerin liseyi bitirme eğilimleri üzerinde en güçlü etkiye sahip değişkenin görev eğilimi olduğunu belirtmektedir. Performans, sosyal ve dişsal güdü de liseyi bitirme eğilimini olumlu etkilese de, bunların etkisi görev eğilimine göre epey düşüktür.

Okula yönelik güdü envanterinin bir diğer faktörü performanstır. Bu faktördeki öğrencilerin yarışma ve sosyal güç elde etme eğiliminde oldukları söylenebilir (McInerney ve Sinclair, 1991). Göreve yönelik güdünün aksine, performansa yönelik güdünün okuldaki iyi oluş hali üzerindeki etkisi anlamlı değildir (McInerney, 2008). Benzer bir şekilde performans güdüsünün eğitim hayatına devam etme üzerindeki etkisi de oldukça düşüktür (King ve 
diğerleri, 2012; McInerney, 2008). Bununla birlikte görev yerine performansa yönelik olarak güdülenen öğrencilerin akademik başarılarının da daha düşük olduğu belirtilmektedir (Lee ve diğerleri, 2014).

Sonraki boyut olan sosyal dayanışma, işbirliği ve sosyal yardımlaşma faktörlerini kapsamaktadır. Sosyal amaçlar için güdülenen öğrencilerin görev eğiliminde olduğu gibi, derinlemesine öğrenme stratejilerini daha çok işe koşmaktadır (King ve diğerleri, 2012). Ancak sosyal güdülenmenin okulu değerli bulma ve sonraki eğitim hayatına devam etme üzerindeki etkisi görev faktörüne göre daha zayıftır (McInerney, 2008). İşbirliği ve sosyal alaka azaldıkça hem okula yönelik güdü olumsuz etkilenmekte hem de akademik başarı düşmektedir (McInerney, 2008). Suliman ve McInerney (2006) Avustralya'da öğrenim gören Lübnan kökenli öğrencilerinin başarıları üzerinde sosyal dayanışma faktörünün etkili olduğunu belirtmiştir.

Okula yönelik güdü envanterinin son boyutu övgü ve ödülü barındıran dışsal pekiştireçtir. Ödül ve övgü gibi dışsal amaçlar için güdülenen öğrencilerin yüzeysel öğrenme stratejilerini daha çok kullandıkları, akademik olarak daha başarısız oldukları, içsel güdülenmenin de düşük olduğu görülmektedir (Bear, Slaughter, Mantz ve Farley-Ripple, 2017; Bolat, 2016; King ve diğerleri, 2012).

$\mathrm{Bu}$ araştırmada elde edilen bulgular doğrultusunda bazı uygulama ve araştırma önerileri sunulabilir. Okula Yönelik Güdü Ölçeğinin faktörlerine ilişkin araştırmalar incelendiğinde, öğrenme öğretme ortamlarında performans ve dışsal güdülenme yerine, görev eğilimi ve sosyal dayanışmaya yönelik güdülenmeyi destekleyecek faaliyetlerin öne çıkarılması gerektiği söylenebilir. Farklı öğrenme öğretme etkinliklerinin öğrencilerin okula yönelik güdülerini nasıl etkilediğini inceleyen deneysel çalışmaların yapılması yararlı olacaktır. Bu yolla hangi öğrenme öğretme etkinliklerinin görev ve sosyal dayanışma boyutlarındaki güdüyü arttırdığı daha net olarak anlaşılabilir. Öğretmenlere görev eğilimi ve sosyal dayanışmayı destekleyen öğrenme öğretme faaliyetleri yürütmeleri önerilebilir. Bununla birlikte dışsal güdülenmeyi arttıran faaliyetlerin daha az kullanılması yararlı olacaktır.

Öte yandan farklı sınıf düzeyi, bölüm ve bölgelerdeki öğrencilerin okula yönelik güdülerini inceleyen betimsel araştırmaları yürütülmesi de var olan durumun anlaşılması açısından yararlı olabilir. Okula yönelik güdünün Türk öğrencilerin akademik başarıları, okula devam etme durumları gibi birçok değişken üzerindeki etkisini inceleyen ilişkisel çalışmalar da yürütülebilir. Bunula birlikte kültürlerarası çalışmalar yürütülerek okula yönelik güdünün anlaşılmasına katkı sunulabilir.

Sonuç olarak bu araştırmada McInerney ve Sinclair (1991) tarafından geliştirilmiş ve farklı kültürlerde geçerliliği kanıtlanmış (Ganotice ve diğerleri, 2012; King ve diğerleri, 2012; Suliman ve McInerney, 2006; Xu ve Barnes, 2011) olan Okula Yönelik Güdü Envanteri Türkçeye çevrilmiş ayrıca ölçeğin orijinalinde bulunan sekiz faktörlü yapının araştırmaya dahil edilen ünevirsetedeki lisans öğrencileri için de geçerli olduğu doğrulanmıştır. Bununla birlikte OYGÖ benzer yapıdaki Okula Yönelik Tutum ve Genel Öz- yeterlik Ölçekleri ile anlamlı ilişkiye sahiptir. Bu doğrultuda OYGÖ’nin ölçüt geçerliğinin de sağlandığı söylenebilir.

\section{Kaynaklar}

Açıkgöz, K. Ü. (2003). Etkili ögrenme ve ögretme. Eğitim Dünyası Yayınları.

Aktaş, O. (2009). Ortalama yükseltme sınavına giren 9. sinf öğrencilerinin okul motivasyonunu etkileyen faktörler (Beykoz örneği) (Yayımlanmamış yüksek lisans tezi). Beykent Üniversitesi, İstanbul.

Akyol, B. (2016). Teacher self-efficacy perceptions, learning oriented motivation, lifelong learning tendencies of candidate teachers: A modeling study. Egitim Arastirmalarl Eurasian Journal of Educational Research, 2016(65), 19-34. doi:10.14689/ ejer.2016.65.02

Alici, D. (2013). Okula Yönelik Tutum Ölçeği ' nin Geliştirilmesi : Güvenirlik ve geçerlik çalışması [Development of an Attitude Scale towards school: A Study on reliability and validity]. Education and Science, 38(168), 318-331. 
Altun, F. (2010). Üstün yetenekli öğrencilerin mükemmeliyetçilik özellikleri, okul motivasyonları, öğrenme stilleri ve akademik başarıları (Yayımlanmamış yüksek lisans tezi). Karadeniz Teknik Üniversitesi, Trabzon.

Ayna, C. (2009). Fen ve teknoloji dersinde birleştirme II (Jigsaw II) yönteminin kullanılmasının ve sosyo-ekonomik düzeyin ögrrencilerin akademik başarl, fen ve teknoloji dersine yönelik tutum ve motivasyon düzeylerine etkisi (Yayımlanmamış yüksek lisans tezi). Karaelmas Üniversitesi, Zonguldak.

Aypay, A. (2010). Genel Öz Yeterlik Ölçeği’nin (GÖYÖ) Türkçe’ye uyarlama çalışması. İnönü Üniversitesi Eğitim Fakültesi Dergisi, 11(2), 113-131.

Bandura, A. (1977). Self-efficacy: Toward a unifying theory of behavioral change. Psychological Review, 84(2), 191-215. doi:10.1037/0033-295X.84.2.191

Bear, G. G., Slaughter, J. C., Mantz, L. S. ve Farley-Ripple, E. (2017). Rewards, praise, and punitive consequences: Relations with intrinsic and extrinsic motivation. Teaching and Teacher Education, 65, 10-20. doi:10.1016/j.tate.2017.03.001

Bolat, Ö. (2016). Beni ödülle cezalandirma: Mutlu ve basarll cocuk yetistirmek icin rehber. Dogan Kitap. Erişim adresi: https://books.google.com.tr/books?id=M-shvgAACAAJ

Eagly, A. H. ve Chaiken, S. (2007). The advantages of an inclusive definition of attitude. Social Cognition, 25(5), 582-602. doi:10.1521/soco.2007.25.5.582

Elliot, A. J. ve Murayama, K. (2008). On the measurement of achievement goals: Critique, illustration, and application. Journal of Educational Psychology, 100(3), 613-628. doi:10.1037/0022-0663.100.3.613

Ersanl1, C. Y. (2015). The Relationship between students' academic self-efficacy and language learning motivation: A study of 8th graders. Procedia-Social and Behavioral Sciences, 199, 472-478. doi:10.1016/j.sbspro.2015.07.534

Erten, P. (2015). Çevrimiçi işbirlikli ögrrenme ortamında e-portfolyo uygulamasının akademik başarıya, tutumlara, motivasyona ve kalıcılı̆̆a etkisi (Yayımlanmamış doktora tezi). Firat Üniversitesi, Elazı̆̆.

Fan, Y.-C., Wang, T.-H. ve Wang, K.-H. (2011). A Web-based model for developing assessment literacy of secondary in-service teachers. Computers \& Education, 57(2), 1727-1740. doi:DOI: 10.1016/j.compedu.2011.03.006

Ganotice, F. A., Bernardo, A. B. I. ve King, R. B. (2012). Testing the factorial invariance of the English and Filipino versions of the inventory of school motivation with bilingual students in the Philippines. Journal of Psychoeducational Assessment, 30(3), 298-303. doi:10.1177/0734282911435459

Greene, B. A., Miller, R. B., Crowson, H. M., Duke, B. L. ve Akey, K. L. (2004). Predicting high school students' cognitive engagement and achievement: Contributions of classroom perceptions and motivation. Contemporary Educational Psychology, 29(4), 462-482. doi:http://dx.doi.org/10.1016/j.cedpsych.2004.01.006

Gürün, O. A. (1991). Psikoloji sözlügü. İstanbul: İnkılâp Kitabevi. Erişim adresi: https://books.google.com.tr/ books?id=BQV1AAAACAAJ

Ho, I. T. ve Hau, K.-T. (2008). Academic achievement in the Chinese context: The role of goals, strategies, and effort. International Journal of Psychology, 43(5), 892-897. doi:10.1080/00207590701836323

Jain, Y. ve Sidhu, G. K. (2013). Relationship between anxiety, attitude and motivation of tertiary students in learning english as a second language. Procedia-Social and Behavioral Sciences, 90 (InCULT 2012), 114-123. doi:10.1016/j.sbspro.2013.07.072

Jöreskog, K. G. ve Sörbom, D. (1993). LISREL 8: structural equation modeling with the SIMPLIS command language. Lincolnwood: Scientific Software International.

Kalaycı, Ş. (2008). SPSS uygulamalı çok değişkenli istatistik teknikleri (3. bs.). Ankara: Asil Yayın Dağıtım.

King, R. B., Ganotice, F. A. ve Watkins, D. A. (2012). Cross-cultural validation of the inventory of school motivation (ISM) in the Asian setting: Hong Kong and the Philippines. Child Indicators Research, 5(1), 135-153. doi:10.1007/s12187-011-9117-3 
Lee, K., Ning, F. ve Goh, H. C. (2014). Interaction between cognitive and non-cognitive factors: The influences of academic goal orientation and working memory on mathematical performance. Educational Psychology: An International Journal of Experimental Educational Psychology, 34(1), 73-91. doi:10.1080/01443410.2013.836158

Maehr, M. L. (1984). Meaning and motivation: Toward a theory of personal investment. R. Ames ve C. Ames (Yay. haz.), Research on motivation in education içinde (C. 1, s. 115-144). New York: AcademicPress.

McInerney, D. (2008). Personal investment, culture and learning: Insights into school achievement across Anglo, Aboriginal, Asian and Lebanese students in Australia. International Journal of Psychology, 43(5), 870-879. doi:10.1080/00207590701836364

McInerney, D. M., Roche, L. A., McInerney, V. ve Marsh, H. W. (1997). Cultural perspectives on school motivation: The relevance and application of Goal Theory. American Educational Research Journal, 34(1), 207-236. doi:10.2307/1163347

McInerney, D. M. ve Sinclair, K. E. (1991). Cross cultural model testing: Inventory of School Motivation. Educational and Psychological Measurement, 51(1), 123-133. doi:10.1177 /0013164491511011

Miller, R. B., Greene, B. A., Montalvo, G. P., Ravindran, B. ve Nichols, J. D. (1996). Engagement in academic work: The role of learning goals, future consequences, pleasing others, and perceived ability. Contemporary Educational Psychology, 21(4), 388-422. doi:http://dx.doi.org/10.1006/ceps.1996.0028

Nasser, R. ve McInerney, D. (2016). Achievement-oriented beliefs and their relation to academic expectations and school achievement among Qatari students. Educational Psychology, 36(7), 1219-1241. doi:10.1080/01443410.2014.993928

Pintrich, P. R. (2000). Multiple goals, multiple pathways: the role of goal orientation in learning and achievement. Journal of Educational Psychology, 92(3), 544-555.

Pintrich, P. R. (2003). A motivational science perspective on the role of student motivation in learning and teaching contexts. Journal of Educational Psychology, 95(4), 667-686. doi:10.1037/0022-0663.95.4.667

Raposo, M., Rico, N. ve Castro, E. (2017). Motivation, self-confidence and anxiety as descriptors of the attitude towards mathematics of the future teachers of basic education in Chile. Pna-Revista De Investigacion En Didactica De La Matematica, 11(3), 181203.

Salomon, G. (1984). Television is "easy" and print is "tough": The differential investment of mental effort in learning as a function of perceptions and attributions. Journal of Educational Psychology, 76(4), 647-658. doi:10.1037/0022-0663.76.4.647

Schunk, D. H., Pintrich, P. R. ve Meece, L. J. (2008). Motivation in education: Theory, research, and applications. New Jersey: Merrill.

Suliman, R. ve McInerney, D. M. (2006). Motivational goals and school achievement: Lebanese-background students in south-western Sydney. Australian Journal of Education, 50(3), 242-264.

Şimşek, Ö. F. (2007). Yapısal eşitlik modellemesine giriş (Temel ilkeler ve LISREL uygulamaları). Ankara: Ekinoks.

Türel, Y. K. (2008). Öğrenme nesneleri ile zenginleştirilmiş öğretim ortamlarının öğrenci başarıları tutumları ve motivasyonları üzerindeki etkisi (Yayımlanmamış yüksek lisans tezi). Frrat Üniversitesi, Elazı̆̆.

Wang, W., Li, X. ve Hsieh, J. J. P.-A. (2013). The contingent effect of personal IT innovativeness and IT self-efficacy on innovative use of complex IT. Behaviour \& Information Technology, 32(11), 1105-1124. doi:10.1080/0144929x.2011.566940

Watkins, D., McInerney, D. ve Akande, A. (2003). An investigation of ethnic differences in the motivation and strategies for learning of students in desegregated South African schools, 34(2), 189-194. doi:10.1177/0022022102250563

Watkins, D., McInerney, D. M. ve Lee, C. (2002). Assessing the school motivation of Hong Kong students. Psychologia, 45(3), 144-154. doi:10.2117/psysoc.2002.144 
Wong, R. (2000). Motivation. Cambridge, UNKNOWN: Cambridge University Press. Erişim adresi: http://ebookcentral.proquest.com/lib/ege/detail.action?docID=157030

$\mathrm{Xu}$, L. ve Barnes, L. L. B. (2011). Measurement invariance of scores from the Inventory of School Motivation across Chinese and U.S. college students. International Journal of Testing, 11(2), 178-210. doi:10.1080/15305058.2010.542357

Yavuz, F. (2006). Okul Motivasyonu Değerlendirme Ölçeğinin yapılandırılması ve güvenirliği (Yayınlanmamış yüksek lisans tezi). Marmara Üniversitesi, İstanbul.

\section{Extended Abstract}

\section{Introduction}

The motivation is defined as the inner drive that stimulates many effects such as persistence required to engage in, maintain and complete a task. People who have high motivation can concentrate on the task intensively and determinedly, and without hesitation. Determining students' motivational levels and analyzing the dependent variables that my affect the motivation can contribute to our understanding of students' current situation. So, valid and reliable scales are needed to determine students' school motivation. However, there aren't any valid and reliable scales that can determine university students' school motivation in Turkish Culture. The Inventory of School Motivation (ISM) was mostly used to determine students' school motivation in many studies in different cultures. The aim of this study is adapting the ISM to Turkish and analyzing the relations between school motivation, attitudes towards school and general self-efficacy.

\section{Method}

The scale has 43 items and measures eight perceived school motivation goals underlying four general goal orientations. Participants respond to each item on a five-point rating scale $(1=$ "Strongly Disagree" to 5 = "Strongly Agree") with higher scores reflecting higher levels of school motivation. The factors are named as task involvement (4 items), effort (7 items), competition (6 items), social power (6 items), affiliation (3 items), social concern (5 items), praise (5 items) and token (7 items). Firstly three experts translated the original scale from English to Turkish and another three experts re-translated the scale to English. Then researcher and an expert selected the most eligible items and the selected items were sent to the expert review (six academicians, two language experts, and six university students) so the final form of Turkish version was prepared. The Turkish version of ISM was administered to 554 university students, and confirmatory factorial analysis (CFA) was conducted to test if the original factorial structure is also valid for Turkish version.

\section{Result and Discussion}

The results of CFA showed that the fit indexes (RMSEA:.068, CFI:.86, SRMR: .084) were between acceptable intervals. The reliability coefficients were calculated as $.90, .84, .87, .89, .86, .84, .91$ for each factors respectively and .93 for the whole scale. So, the results show that Turkish version of ISM is valid and reliable for university students.

Then the criterion validity of ISM's Turkish version was tested by examining the correlation between ISM, Attitudes Towards School Scale (ATSS) and General Self-Efficacy Scale (GSES). ATSS was developed for high school students, and it has 20 items with three factors. Participants respond to each item on a five-point rating scale $(1=$ "Strongly Disagree" to $5=$ "Strongly Agree"). CFA was conducted to test the psychometric properties of ATSS for university students. The results show that three factored structure of ATSS was also confirmed for university students (RMSEA: .074, CFI: .91, SRMR: .049). The reliability scores of the ATSS was calculated as 0,$91 ; 0,87 ; 0,81$ and 0,79 for the whole and factors of the ATSS respectively. GSES was adapted to Turkish for university students. The scale has ten items within two factors. Participants respond to each item on a four-point rating scale 
(1="Completely False", 2="Mostly False", 3="Mostly True", 4="Completely True"). The reliability coefficients calculated for factors were found to be .72 and .85 respectively.

The data were collected from 784 university students, who had not attended the first implementation of ISM, to test the correlation between ISM, ATSS, and GSES. A structural equation model (SEM) was conducted to test the correlation between these three variables. The results of SEM show that the fit indexes between data and the model were between acceptable intervals (RMSEA:.072, GFI..94, AGFI..91, NFI..91). So it can be said that the ISM has significant correlations with similar structured scales and it means that criterion validity of ISM was also confirmed.

The results of this study are parallel to those of many studies reported in the literature. The ISM has been adapted to many cultures such as Australian, American, Europen, and Asian. It is also valid and reliable for Turkish culture. The first dimension of the ISM is the task and contains two sub-dimensions (task involvement, effort). The students who have high scores from that factor don't hesitate to make an effort to finish a task. These students mostly use deep learning strategies and also have the highest intention for further education. Also, task dimension's effect on well-being at school is statistically significant.

The second dimension is called performance. This dimension also has two subdimensions called competition and social power. Unlike task dimension, performance dimension's effect on well-being at school is not significant.

The other dimension is social solidarity, which contains affiliation and social concern. Students who are motivated for social solidarity use deep learning strategies like task involvement. However, the effect of social solidarity on the intention for further education is lower than that of task involvement.

The last dimension is extrinsic rewards and contains praise and token rewards subdimensions. Students who are motivated extrinsically use surface learning strategies mostly, and academically less successful than intrinsically motivated students.

Some suggestions may be given based on these findings. Descriptive studies may analyze the school motivations of university students with larger samples. Some experimental studies may be conducted to clarify how different instructional implementations may affect students' school motivation. Also, cross-cultural studies may help us to understand students' school motivation globally.

As a result, the ISM, which was developed by McInerney and Sinclair and adapted to many cultures, was adapted to Turkish Culture through this study. The eight factored structure of the scale was also valid for Turkish Culture. 